\title{
Anti-inflammatory Activities of $\alpha$-Truxillic Acid Derivatives and Their Monomer Components
}

\author{
Yu-Ming Chi, ${ }^{*, a}$ Motoyuki Nakamura, ${ }^{a}$ Toyokichi Yoshizawa, ${ }^{a}$ Xi-Ying Zhao, ${ }^{a}$ Wen-Mei Yan, ${ }^{b}$ \\ Fumio Hashimoto, ${ }^{c}$ Junei Kinjo, ${ }^{c}$ Toshihiro Nohara, ${ }^{*, c}$ and Shinobu Sakurada ${ }^{d}$ \\ ${ }^{a}$ Seiwa Pharmaceutical. Ltd.; 187-11 Usuba, Hanakawa-machi, Kitaibaraki, Ibaraki 319-1535, Japan: ${ }^{b}$ Beijing \\ University of Traditional Chinese Medicine and Pharmacy; Beijing 100029, China: ${ }^{c}$ Faculty of Pharmaceutical Sciences, \\ Kumamoto University; 5-1 Oe-Honmachi, Kumamoto 862-0973, Japan: and d Department of Pharmacology, Tohoku \\ College of Pharmacy; 4-4-1 Komatsushima, Aoba-ku, Sendai 981-0905, Japan. \\ Received February 28, 2005; accepted May 5, 2005
}

\begin{abstract}
The anti-inflammatory activities of $\alpha$-truxillic acid (1) and 4,4'-dihydroxy- $\alpha$-truxillic acid (2) as well as their monomer components $(E)$-cinnamic acid (3) and $(E)$-p-coumaric acid (4) were evaluated in the formalin test. $\alpha$ Truxillic acid (1) and its derivative 4,4' -dihydroxy- $\alpha$-truxillic acid (2) exhibited significant activity against inflammatory pain response, while their monomer components $(E)$-cinnamic acid (3) and (E)-p-coumaric acid (4) did not show any activity against either neurogenic or inflammatory pain responses induced by formalin in mice. These results suggested that the dimeric structure might play an important role for the expression of anti-inflammatory activity. Furthermore, in order to gain information on their potencies, their anti-inflammatory activities were compared with that of incarvillateine (5) which contains the same dimeric structure and showed more potent antinociceptive activity than morphine in the formalin test. The activities of $\alpha$-truxillic acid (1) and 4,4'-dihydroxy- $\alpha$-truxillic acid (2) at the dose of $40 \mathrm{mg} / \mathrm{kg}$ against inflammatory pain response were equal to that of incarvillateine at doses of $20 \mathrm{mg} / \mathrm{kg}$.
\end{abstract}

Key words $\alpha$-truxillic acid; $4,4^{\prime}$-dihydroxy- $\alpha$-truxillic acid; dimer; incarvillateine; anti-inflammatory activity; formalin test

In a previous report, we disclosed that incarvillateine (5), which is thought to be formed by cyclodimerisation of incarvine $\mathrm{C}$ (an ester of ferulic acid and incarvilline) or by diesterification of incarvilline and 3,3'-dimethoxy-4,4'-dihydroxy$\alpha$-truxillic acid, showed more potent antinociceptive activity than morphine in the formalin-induced pain model in mice. ${ }^{1)}$ In addition, we reported that 3,3'-demethoxy-4,4'-dehydroxyincarvillateine (a new synthetic derivative of 5) exhibited activity equal to that of incarvillateine (5), but that incarvine $\mathrm{C}$ and ferulic acid did not exhibit any activity against either neurogenic or inflammatory pain responses in the formalin test. ${ }^{2)}$ In the course of our investigation on the structure-antinociceptive activity of incarvillateine (5), we concluded that the monoterpene alkaloid moiety incarvilline and dimeric structure played an important roles in the expression of activities against neurogenic and inflammatory pain responses respectively. $^{2)}$

In order to obtainmore the convincing evidence, several related compounds such as $\alpha$-truxillic acid (1) and its derivative $4,4^{\prime}$-dihydroxy- $\alpha$-truxillic acid (2) as well as their monomer components (E)-cinnamic acid (3) and (E)-pcoumaric acid (4) were prepared (Fig. 1) and their activities were evaluated in the formalin test. These monomeric and dimeric phenolic acids are widely distributed in plants and are found either free or bound to tissue components. ${ }^{3-5)}$

\section{MATERIALS AND METHODS}

Chemicals (E)-Cinnamic acid (3) and Tween 80 (polyoxyethylene sorbitan monooleate) were purchased from Nacalai Tesque (Kyoto, Japan). (E)-p-Coumaric acid (4) was purchased from Tokyo Kasei (Tokyo, Japan). Ringer solution was obtained from Fuso Pharmaceutical (Osaka, Japan).

General ${ }^{1}$ H-NMR: JEOL JNM-GX 500 NMR, int. stan- dard (TMS); The other instruments and reagents used in this study were the same as those described in a preceding paper. ${ }^{6)}$

Synthesis of $\alpha$-Truxillic Acid (1) (E)-Cinnamic acid (3) was irradiated in the solid state. (E)-Cinnamic acid crystals $(1.0 \mathrm{~g})$ were dispersed in hexane in a Pyrex flask. The flask was then irradiated with a $400 \mathrm{~W}$ high-pressure mercury lamp (Riko, Japan, UVL-400HA) at room temperature. After $2 \mathrm{~d}$, the product was filtered off, washed with ether and recrystallized twice from ethanol to give $750 \mathrm{mg}$ of white crystals as $\alpha$-truxillic acid. mp $274-275^{\circ} \mathrm{C}$ (lit. $274-278^{\circ} \mathrm{C}$ ). Negative FAB-MS $m / z$ (rel. int.): $295[\mathrm{M}-\mathrm{H}]^{-} .{ }^{1} \mathrm{H}-\mathrm{NMR}$ $\left(\mathrm{DMSO}-d_{6}\right) \delta: 3.81\left(2 \mathrm{H}, \mathrm{m}, \beta, \beta^{\prime}-\mathrm{H}\right), 4.28\left(2 \mathrm{H}, \mathrm{m}, \alpha, \alpha^{\prime}-\mathrm{H}\right)$, $7.22-7.33\left(10 \mathrm{H}\right.$, aromatic-H). ${ }^{7,8)}$

Synthesis of 4,4'-Dihydroxy- $\alpha$-truxillic Acid (2) (E)-p-

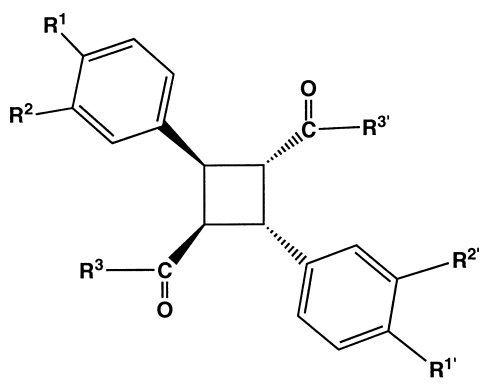

$$
\begin{aligned}
& \text { 1: } \mathrm{R}^{1}=\mathrm{R}^{1}=\mathrm{R}^{2}=\mathrm{R}^{2}=\mathrm{H} \\
& \mathrm{R}^{3}=\mathrm{R}^{3^{\prime}}=\mathrm{OH} \\
& \text { 2: } \mathrm{R}^{1}=\mathrm{R}^{1}=\mathrm{OH}, \mathrm{R}^{2}=\mathrm{R}^{2}=\mathrm{H} \\
& \mathrm{R}^{3}=\mathrm{R}^{3}=\mathrm{OH}
\end{aligned}
$$

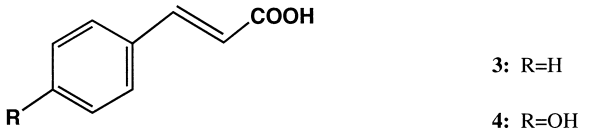

Fig. 1. Structures of $\alpha$-Truxillic Acid Derivatives and Their Monomer Components 
Coumaric acid (4) was also irradiated in the solid state. $(E)$ $p$-Coumaric acid crystals $(1.0 \mathrm{~g})$ were dispersed in hexane in a Pyrex flask. The flask was then irradiated with a $400 \mathrm{~W}$ high-pressure mercury lamp (Riko, Japan, UVL-400HA) at room temperature. After $1 \mathrm{~d}$, the product was filtered off, washed with ether, and recrystallized twice from ethanol to give $980 \mathrm{mg}$ of white crystals as $4,4^{\prime}$-dihydroxy- $\alpha$-truxillic acid. $\mathrm{mp}>300{ }^{\circ} \mathrm{C}$ (lit. $340{ }^{\circ} \mathrm{C}$ ). Anal. Calcd for $\mathrm{C}_{18} \mathrm{H}_{16} \mathrm{O}_{6}: \mathrm{C}$, 65.85\%; H, 4.91\%. Found: C, 65.75\%; H, 4.92\%. Positive FAB-MS $m / z$ (rel. int.): $329[\mathrm{M}+\mathrm{H}]^{+} .{ }^{1} \mathrm{H}-\mathrm{NMR}$ (DMSO- $d_{6}$ ) $\delta$ : $3.64\left(2 \mathrm{H}, \mathrm{m}, \beta, \beta^{\prime}-\mathrm{H}\right), 4.13\left(2 \mathrm{H}, \mathrm{m}, \alpha, \alpha^{\prime}-\mathrm{H}\right), 6.69(4 \mathrm{H}, \mathrm{d}$, $\left.J=8.8 \mathrm{~Hz}, 3,3^{\prime}, 5,5^{\prime}-\mathrm{H}\right), 7.11\left(4 \mathrm{H}, \mathrm{d}, J=8.8 \mathrm{~Hz}, 2,2^{\prime}, 6,6^{\prime}-\right.$ H). ${ }^{9)}$

Formalin Test and Treatments This method represented a modification of that described by Dubuisson and Dennis. ${ }^{10)}$ Male ddy mice $(25 \mathrm{~g} \pm 5)$ were used. The test drugs (40 mg/kg for 1, 2, 3 and 4; $20 \mathrm{mg} / \mathrm{kg}$ for 5) were prepared as suspensions with $0.5 \%$ Tween 80 /saline and intraperitoneally administered $10 \mathrm{~min}$ prior to the injection of an inducer $(1 \%$ formalin/saline, 201). The mice were observed for $30 \mathrm{~min}$ and the time that the mice spent licking the injected right hindpaw was recorded. The nociceptive scores normally peaked 0 to $10 \mathrm{~min}$ after formalin injection (early phase) and 10 to $30 \mathrm{~min}$ (late phase) after the injection, representing the neurogenic and inflammatory pain responses, respectively. ${ }^{11)}$ The time spent licking the injected paw was recorded and the data were expressed as total licking time in the early phase and late phase.

Statistical Analysis All values are expressed as the mean \pm S.E. $(n=10)$. For statistical analysis, one-way analysis of variance combined with Dunnett's multiple range test for multiple comparisons were used. Differences were considered significant at $p<0.01$.

\section{RESULTS AND DISCUSSION}

The formalin-induced licking response has been used as a model for evaluating new analgesics. ${ }^{112)}$ The duration of the nociceptive response induced by formalin can be divided into two phases. The early phase is from 0 to $10 \mathrm{~min}$ after formalin injection and the late phase is from 10 to $30 \mathrm{~min}$ after the injection. The two phases have obvious differential properties. The pain in the early phase is evoked by the direct stimulation of the nerve fibers, while and that in the late phase is due to the inflammatory response. Centrally-acting drugs such as morphine inhibit both the early and late phases equally. On the other hand, peripheral-acting drugs such as aspirin inhibit only the late phase.

Intraperitoneal administration of $\mathbf{1 ,} \mathbf{2}, \mathbf{3}$ and $\mathbf{4}$ at doses of $40 \mathrm{mg} / \mathrm{kg}$ and incarvillateine (5) at a dose of $20 \mathrm{mg} / \mathrm{kg}$, showed significant antinociceptive activity against both neurogenic (early phase) and inflammatory (late phase) pain responses induced by formalin. $\alpha$-Truxillic acid (1) and its derivative $4,4^{\prime}$-dihydroxy- $\alpha$-truxillic acid (2) at doses of $40 \mathrm{mg} / \mathrm{kg}$ showed significant activity against the inflammatory pain response that was as strong as $\mathbf{5}$ at a dose of $20 \mathrm{mg} / \mathrm{kg}$, while their monomer components $(E)$-cinnamic acid (3) and (E)-p-coumaric acid (4) did not show any activity against either the neurogenic or inflammatory pain responses (Figs. 2, 3).

Incarvillateine (5) is representative of the novel monoter-

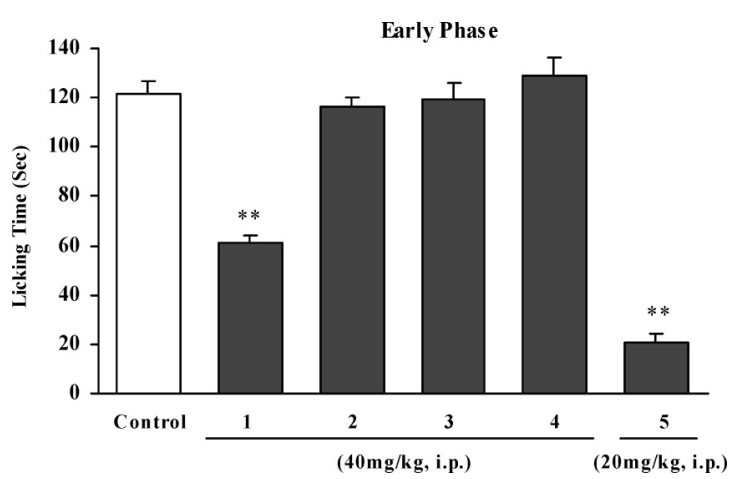

Fig. 2. Activities of $\alpha$-Truxillic Acid (1), 4,4'-Dihydroxy- $\alpha$-truxillic Acid (2), (E)-Cinnamic acid (3), (E)-p-Coumaric Acid (4) and Incarvillateine (5) against Neurogenic Pain Response (Early Phase) Induced by Formalin in Mice

Each value represents mean \pm S.E. $(n=10)$. Significant differences $(p=0.01)$ between control and drug-treated groups are indicated by $* *$.

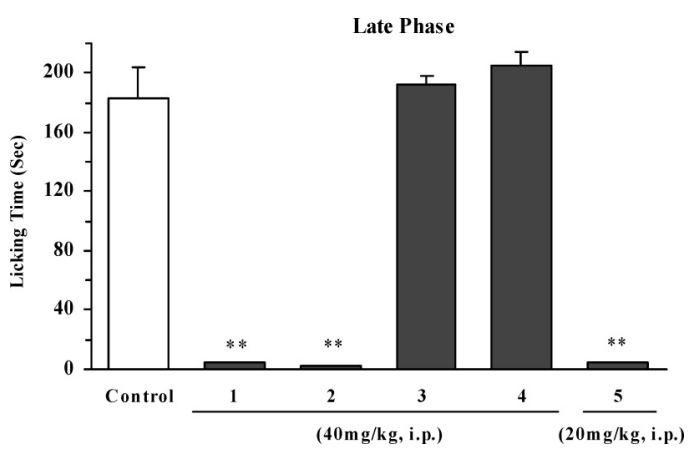

Fig. 3. Activities of $\alpha$-Truxillic Acid (1), 4,4'-Dihydroxy- $\alpha$-truxillic Acid (2), (E)-Cinnamic Acid (3), (E)-p-Coumaric Acid (4) and Incarvillateine (5) against Inflammatory Pain Response (Late Phase) Induced by Formalin in Mice

Each value represents mean \pm S.E. $(n=10)$. Significant differences $(p<0.01)$ between control and drug-treated groups are indicated by $* *$.

pene alkaloidal derivatives derived from Incarvillea sinensis and displayed more potent antinociceptive activity than morphine in the formalin test. Structure-antinociceptive activity studies of incarvillateine suggested that the dimeric structure played an important role in the expression of its anti-inflammatory activity. $\alpha$-Truxillic acid has the same dimeric structure as that of incarvillateine (5). In order to investigate the function of dimeric structure in the anti-inflammatory activities of $\alpha$-truxillic acid and its derivatives, $\alpha$-truxillic acid (1) and $4,4^{\prime}$-dihydroxy- $\alpha$-truxillic acid (2) as well as their monomer components (E)-cinnamic acid (3) and (E)-pcoumaric acid (4) were prepared and their activities evaluated in the formalin test.

In the present study, $\alpha$-truxillic acid (1) and its derivative $4,4^{\prime}$-dihydroxy- $\alpha$-truxillic acid (2) at doses of $40 \mathrm{mg} / \mathrm{kg}$ showed weak or no activity against the neurogenic pain response induced by formalin, while the activity against the inflammatory pain response was equal to that of incarvillateine (5) at the dose of $20 \mathrm{mg} / \mathrm{kg}$. Meanwhile their monomer components $(E)$-cinnamic acid (3) and $(E)$-p-coumaric acid (4) at doses of $40 \mathrm{mg} / \mathrm{kg}$ did not show any activity against either the neurogenic or inflammatory pain responses in the formalin test. These results suggested that the dimeric structure played an important role in the expression of activity against 
formalin-induced inflammatory pain response, but seemed to be ineffective in preventing neurogenic pain response. In our previous report of the structure-antinociceptive activity of incarvillateine (5), 3,3'-demethoxy-4,4'-dehydroxyincarvillateine exhibited equal antinociceptive activity to that of $\mathbf{5}$, but incarvine $\mathrm{C}$ (the monomer component of 5) and ferulic acid did not show any activity in the formalin test. These results indicated that the monoterpene alkaloid moiety incarvilline and dimeric structure of incarvillateine (5) were mainly responsible for the activities against the neurogenic and inflammatory pain responses, respectively. Furthermore, this suggestion was supported by the result that $(E)$-cinnamic acid (3) and (E)-p-coumaric acid (4) did not show any activity against either neurogenic or inflammatory pain responses induced by formalin.

In conclusion, these results clearly indicated that $\alpha$-truxillic acid derivatives are another group of leading compounds that are important for developing a new type of anti-inflammatory drugs. The result also confirmed that the dimeric structure plays an important role in the activity of incarvillateine (5) against the inflammatory pain response in the formalin test. It is possible that much stronger anti-inflammatory compounds will appear by synthesizing other $\alpha$-truxillic acid derivatives. Further investigation is required to develop potent anti-inflammatory substances with dimeric structure and to elucidate the precise mechanisms underlying these activities.

\section{REFERENCES}

1) Nakamura M., Chi Y. M., Yan W. M., Nagasugi Y., Yoshizawa T., Irino N., Hashimoto F., Kinjo J., Nohara T., Sakurada S., J. Nat. Prod., 62, 1293-1294 (1999).

2) Nakamura M., Chi Y. M., Yan W. M., Nagasugi Y., Yoshizawa T., Irino N., Hashimoto F., Kinjo J., Nohara T., Sakurada S., Planta Medica, 67, 114-117 (2001).

3) Hartley R. D., Whatley F. R., Harris P. J., Phytochemistry, 27, 349351 (1988).

4) Ford C. W., Hartley R. D., J. Sci. Food Agric., 46, 301-310 (1989).

5) Ford C. W., Hartley R. D., J. Sci. Food Agric., 50, $29-43$ (1990).

6) Chi Y. M., Hashimoto F., Yan W. M., Nohara T., Phytochemistry, 46, $763-769$ (1997).

7) Montaudo G., Caccamese S., J. Org. Chem., 38, 710 -716 (1973).

8) Baracchi A., Chimichi S., Sio F. D., Donati D., Nesi R., Sarti-Fantoni P., Heterocycles, 24, 2863-2870 (1986).

9) Morrison W. H., Hartley R. D., Himmelsbach D. S., J. Agric. Food Chem., 40, 768-771 (1992).

10) Dubuisson D., Dennis S. G., Pain, 4, 161-174 (1977).

11) Hunskaar S., Hole K., Pain, 30, 103-114 (1987).

12) Shibata M., Ohkubo T., Takahashi H., Inoki R., Pain, 38, 347-352 (1989). 